\title{
Os Núcleos de Estudo em Agroecologia e Produção Orgânica (NEA) enquanto mecanismos de desenvolvimento regional: algumas considerações
}

\author{
Jaqueline Mallmann Haas ${ }^{1}$ \\ Anelise Graciele Rambo ${ }^{2}$ \\ Jairo Alfredo Genz Bolter ${ }^{3}$
}

Resumo: Cada vez mais, o mercado mundial de alimentos é marcado por um processo de oligopolização, no qual grandes corporações transnacionais produzem e ofertam alimentos padronizados. No Brasil, a criação de Núcleos de Agroecologia e Produção Orgânica (NEAs), via políticas federais e interação com Instituições de Ensino Superior, representa experiências que habilitam a construção de sistemas agroalimentares alternativos, que reconhecem saberes dos agricultores familiares, fortalecem relações mais sustentáveis com o ambiente e contribuem com a segurança e soberania alimentar. São atualmente mais de 150 iniciativas. Considerando esse contexto, realizam-se análises com base em uma revisão teórica sobre a trajetória e as repercussões territoriais dos NEAs no Brasil, passando ao caso específico do Litoral Norte do Rio Grande do Sul. Essa região, com histórica existência de produção agroecológica e orgânica, destaca-se pela dificuldade de comercialização in loco. Neste caso, investiga-se as repercussões territoriais da implementação do NEA Litoral Norte junto ao Campus da Universidade Federal do Rio Grande do Sul, em especial, a organização de um grupo de consumidores, para a estruturação de compra direta dos produtores. Além disso, as ações no Núcleo abrangem reuniões e diálogos com atores sociais e políticos que atuam nos temas políticas públicas, agricultura familiar e agroecologia. Os resultados apontam que as experiências que perpassam os NEAs têm a potencialidade de constituir circuitos curtos de comercialização, mais sustentáveis do ponto de vista ambiental, econômico e cultural, contribuindo assim para a promoção do desenvolvimento regional.

Palavras-chave: Consumo. Produção. Agroecologia. Universidade. NEA.

Abstract: Increasingly, the world food market is marked by a process of oligopolization, in which large transnational corporations produce and offer standardized food. In Brazil, the creation of Agroecology and Organic Production Centers (NEA), via federal policies and interaction with Higher Education Institutions, represents experiences that enable the construction of alternative agro-food systems, which recognize the knowledge of family farmers, strengthen more sustainable relationships with the environment and contribute to food security and sovereignty. There are currently more than 150 initiatives. Considering this context, analyzes are carried out based on a theoretical revision on the trajectory and territorial repercussions of the NEAs in Brazil, going to the specific case of the North Coast of Rio Grande do Sul. This region, with historical existence of agroecological and organic production, stands out due to the difficulty of marketing in loco. In this case, we investigate the territorial repercussions of the implementation of NEA North Coast next to the Campus of the Federal University of Rio Grande do Sul, in particular, the organization of a group of consumers, for the structuring of direct purchase of the producers. In addition, the actions in the Nucleus include meetings and dialogues with social and political actors who work on public policy, family agriculture and agroecology. The results indicate that the experiences that pass through the NEAs have the potential to constitute short circuits of

\footnotetext{
${ }^{1}$ Doutora em Extensão Rural, Professora Adjunta do Departamento Interdisciplinar, Universidade Federal do Rio Grande do Sul (UFRGS). haasjaqueline@gmail.com

2 Doutora em Desenvolvimento Rural, Professora Adjunta do Departamento Interdisciplinar, Universidade Federal do Rio Grande do Sul (UFRGS) e do Programa de Pós-Graduação em Agroecologia e Desenvolvimento Rural Sustentável, Universidade Federal da Fronteira Sul (UFFS). ane_rambo@yahoo.com.br

${ }^{3}$ Doutor em Desenvolvimento Rural, Professor Adjunto do Departamento Interdisciplinar, Universidade Federal do Rio Grande do Sul (UFRGS). jairobolter@ufrgs.br
} 
commercialization, more sustainable from an environmental, economic and cultural point of view, contributing to the promotion of regional development.

Keywords: Consumption. Production. Agroecology. University. NEA.

\section{Introdução}

Os dados do Relatório Anual das Nações Unidas sobre Segurança Alimentar e Nutricional de 2017 indicaram que, após quase uma década de declínio, o número de pessoas afetadas pela fome no mundo aumentou novamente, havendo 815 milhões de habitantes nessa situação, o que representa $11 \%$ da população mundial sofrendo de desnutrição crônica em 2016. Em 2017, 124 milhões necessitaram de assistência alimentar de emergência em comparação com os 108 milhões de 2016. Paralelo à fome, cresce o problema da obesidade. Segundo o mesmo relatório da ONU, há 641 milhões de adultos obesos, o que corresponde a $13 \%$ do total de adultos do planeta. Quanto às crianças, 41 milhões, menores de 5 anos, apresentam sobrepeso e ainda, 613 milhões (cerca de 33\% do total) de mulheres em idade reprodutiva afetadas por anemia.

Pode-se afirmar então que um dos maiores desafios a ser enfrentado desde agora e pelas próximas décadas, refere-se a como assegurar à população mundial crescente, que deverá alcançar 10 bilhões de pessoas até 2050, não apenas o acesso a alimentos suficientes, mas alimentos com qualidade e diversidade de modo a satisfazer suas necessidades nutricionais. Para tal, o relatório indica que a produção de alimentos deverá aumentar em $50 \%$ ao nível global para atender este crescimento populacional. Nesse cenário, tem se propalado o Brasil enquanto país com grande potencial quanto ao crescimento na produção de alimentos. O Departamento de Agricultura dos Estados Unidos (USDA) calcula que o país deva alavancar sua produção em cerca de $40 \%$, enquanto que países como China (15\%), a União Europeia (12\%), Estados Unidos (10\%), Canadá (9\%), Austrália (9\%) e Rússia (7\%) também devem apresentar incrementos até 2027.

O Relatório Projeções do Agronegócio Brasil 2016/17 a 2026/27, elaborado pelo Ministério da Agricultura, Pecuária e Abastecimento (MAPA), estima que a produção de grãos deva crescer $24 \%$ no período, destacando-se milho, soja e trigo. Já a produção de carnes (bovina, suína e aves) deverá ter um crescimento de $28 \%$. Diante de tais projeções, é 
possível levantar diversas questões: que tipo de alimentação estará sendo produzida para a população brasileira e mundial? Não seria este padrão de consumo um elemento chave para o aumento da obesidade no mundo? Dessa maneira, não se está fomentando o mesmo modelo que tem gerado guerras e conflitos que, aliadas a fenômenos naturais como secas, tem gerado migrações em massa e fome?

O aumento concomitante da fome e da obesidade é mais uma mostra da crise da modernidade da qual trata Beck (2009). A sociedade está sentindo os efeitos e limites do sistema baseado no progresso, na razão, na cientificidade, no individualismo e na busca desenfreada por crescimento econômico - ou seja, na forma de desenvolvimento que dá suporte ao projeto da modernidade. Entende-se que a autoconfrontação da qual trata o autor expressa-se na temática aqui discutida, ao refletir sobre um número crescente de consumidores que optam, sobretudo nos países desenvolvidos, mas não exclusivamente, por alimentos mais saudáveis, locais, frescos, consumidores que substituem o fast food pelo slow food, como aponta a própria FAO (2018). Boisier (2001) corrobora afirmando que, na medida em que se reconhece no desenvolvimento um sistema complexo, axiológico, multidimensional, construtivista, qualitativo em sua essência e intangível por consequência, o paradigma que vem dominando o desenvolvimento científico da modernidade deixa de ser útil para entender o desenvolvimento por seu caráter reducionista, mecanicista e linear. Neste sentido, entender o desenvolvimento requer enfoques holísticos, sistêmicos e recursivos.

Os programas, projetos, ações de desenvolvimento, hegemonicamente, seguem o padrão da modernidade. Alerta Porto Gonçalves (2004) que a ciência tem sido desenvolvida para tornar mais eficiente a produção de biomassa nas regiões temperadas (que dispõem de menor intensidade de energia solar em relação às regiões tropicais). Um contrassenso que só se explica pela importância do conhecimento técnico-científico e da regulação jurídica da propriedade (patentes e direitos de propriedade intelectual individual) para os países hegemônicos e para as grandes corporações, que detém o monopólio do conhecimento específico, cada vez mais dependente de recursos para a pesquisa e desenvolvimento.

Assim, fortalecem-se os impérios alimentares, entendidos por Ploeg (2008) como o modo de ordenamento fortemente centralizado, constituído por grandes empresas de processamento e comercialização de alimentos, operando em escala mundial. Para Guzmán (2007), a globalização agroalimentar ameaça o patrimônio cultural e material agropecuário, 
rural e alimentar e contribuiu também para aprofundar a crise ecológica na qual vivemos. A alteração do equilíbrio dos agroecossistemas entrelaça-se com os mecanismos de exclusão social que acompanham a crescente dependência do mercado.

Mediante o cenário descrito, intensificam-se discussões no âmbito social, acadêmico e político acerca dos circuitos curtos e descentralizados de comercialização (Renting; Marsden; Banks, 2003; Marsden, Banks, Bristow, 2000) que aproximam produção e consumo, tais como feiras de produtores, entrega de cestas, pequenas lojas de produtores, venda nas propriedades decorrentes do agroturismo, mercados institucionais, dentre outras. Diante dessa alternativa, a agricultura familiar assume papel fundamental, já que é responsável por cerca de $80 \%$ da produção mundial de alimentos, segundo a ONU.

No Brasil, a criação de Núcleos de Agroecologia e Produção Orgânica (NEAs), via políticas federais e interação com Instituições de Ensino Superior, representa experiências que habilitam a construção de sistemas agroalimentares alternativos, que reconhecem saberes dos agricultores familiares, fortalecem relações mais sustentáveis com o ambiente e contribuem com a segurança e soberania alimentar. São atualmente mais de 150 iniciativas, espalhadas pelo país, conforme contabilizado no IV Encontro Nacional de Agroecologia (2017).

Considerando esse contexto, no presente trabalho, realizam-se análises com base em uma revisão teórica sobre a trajetória e as repercussões territoriais dos NEAs no Brasil, passando ao caso específico do Litoral Norte do Rio Grande do Sul. Essa região, com histórica existência de produção agroecológica e orgânica, especialmente na cadeia produtiva dos hortifrutigranjeiros, destaca-se pela dificuldade de comercialização in loco. Municípios de expressão significativa em termos populacionais, não dispõem de centros de comercialização para produtos agroecológicos e/ou orgânicos. Em detrimento, grande parte da produção da região acaba abastecendo os mercados metropolitanos. Neste caso, investiga-se as repercussões territoriais da implementação do NEA Litoral Norte junto ao Campus Litoral da Universidade Federal do Rio Grande do Sul, em especial, a organização de um grupo de consumidores, para a estruturação de compra direta dos produtores da região.

Para tanto, este trabalho está organizado em cinco seções, incluindo esta introdução. Na segunda seção são apresentadas discussões sobre circuitos curtos de comercialização e sua relação com uma alimentação mais saudável e com a promoção do desenvolvimento regional. Na sequência tratar-se-á das experiências dos NEAs no Brasil para em seguida 
abordar o caso do Litoral Norte. Por fim são apresentadas as considerações finais e as referências bibliográficas.

\section{Circuitos curtos de comercialização, alimentação saudável e desenvolvimento regional}

No debate internacional, vale destacar que o acesso à alimentação compõe a Declaração Universal dos Direitos Humanos, em seu artigo 25, a qual reconhece que toda pessoa tem direito a um nível de vida adequado que assegure, assim como a sua família, saúde, bem-estar e, em especial, alimentação. Recentemente, os Objetivos do Desenvolvimento Sustentável (ODS) aproximaram ainda mais os temas fome, segurança alimentar e nutricional e agricultura, abarcados pelo objetivo 2: Acabar com a fome, alcançar a segurança alimentar e melhoria da nutrição e promover a agricultura sustentável.

Do ODS 2 destaca-se as seguintes ações: I) aumentar a produtividade agrícola e a renda dos pequenos produtores de alimentos, particularmente das mulheres, povos indígenas, agricultores familiares, pastores e pescadores, inclusive por meio de acesso seguro e igual à terra, outros recursos produtivos e insumos, conhecimento, serviços financeiros, mercados e oportunidades de agregação de valor e de emprego não agrícola; II) garantir sistemas sustentáveis de produção de alimentos e implementar práticas agrícolas resilientes que ajudem a manter os ecossistemas; III) manter a diversidade genética de sementes, plantas cultivadas, animais de criação e domesticados e suas respectivas espécies selvagens, inclusive por meio de bancos de sementes e plantas diversificados e bem geridos em nível nacional, regional e internacional; dentre outros. O alcance do referido objetivo demanda o envolvimento de múltiplos atores, inclusive produtores e consumidores no planejamento e implementação de ações sinérgicas. No quadro 1, a frente, é possível verificar o ODS na íntegra.

Defende-se que o alcance da soberania e da segurança alimentar e nutricional, de modo a atender ao direito humano à alimentação e ao ODS 2, não será garantida pelo fortalecimento das cadeias longas, expresso nas projeções do USDA e do MAPA, por meio da exportação de produtos primários ou mesmo commodities processadas.

A cada ano que passa, aumentam os problemas relacionados ao meio ambiente e a saúde humana. Um dos embriões desses problemas está centralizado na forma como o 
homem se relaciona com a natureza. A falta de cuidado para com o meio ambiente se acentua em especial no meio rural, onde produtores de forma descontrolada atuam em prol da maximização da produção agrícola e agropecuária.

\section{Quadro 1 - Objetivos do Desenvolvimento Sustentável (ODS) - Objetivo 2}

2.1 Até 2030, acabar com a fome e garantir o acesso de todas as pessoas, em particular os pobres e pessoas em situações vulneráveis, incluindo crianças, a alimentos seguros, nutritivos e suficientes durante todo o ano

2.2 Até 2030, acabar com todas as formas de desnutrição, incluindo atingir, até 2025 , as metas acordadas internacionalmente sobre nanismo e caquexia em crianças menores de cinco anos de idade, e atender às necessidades nutricionais dos adolescentes, mulheres grávidas e lactantes e pessoas idosas

2.3 Até 2030, dobrar a produtividade agrícola e a renda dos pequenos produtores de alimentos, particularmente das mulheres, povos indígenas, agricultores familiares, pastores e pescadores, inclusive por meio de acesso seguro e igual à terra, outros recursos produtivos e insumos, conhecimento, serviços financeiros, mercados e oportunidades de agregação de valor e de emprego não agrícola.

2.4 Até 2030, garantir sistemas sustentáveis de produção de alimentos e implementar práticas agrícolas resilientes, que aumentem a produtividade e a produção, que ajudem a manter os ecossistemas, que fortaleçam a capacidade de adaptação às mudanças climáticas, às condições meteorológicas extremas, secas, inundações e outros desastres, e que melhorem progressivamente a qualidade da terra e do solo

2.5 Até 2020 , manter a diversidade genética de sementes, plantas cultivadas, animais de criação e domesticados e suas respectivas espécies selvagens, inclusive por meio de bancos de sementes e plantas diversificados e bem geridos em nível nacional, regional e internacional, e garantir o acesso e a repartição justa e equitativa dos benefícios decorrentes da utilização dos recursos genéticos e conhecimentos tradicionais associados, como acordado internacionalmente

2.a Aumentar o investimento, inclusive via o reforço da cooperação internacional, em infraestrutura rural, pesquisa e extensão de serviços agrícolas, desenvolvimento de tecnologia, e os bancos de genes de plantas e animais, para aumentar a capacidade de produção agrícola nos países em desenvolvimento, em particular nos países menos desenvolvidos

2.b Corrigir e prevenir as restrições ao comércio e distorções nos mercados agrícolas mundiais, incluindo a eliminação paralela de todas as formas de subsidios à exportação e todas as medidas de exportação com efeito equivalente, de acordo com o mandato da Rodada de Desenvolvimento de Doha

2.c Adotar medidas para garantir o funcionamento adequado dos mercados de commodities de alimentos e seus derivados, e facilitar o acesso oportuno à informação de mercado, inclusive sobre as reservas de alimentos, a fim de ajudar a limitar a volatilidade extrema dos preços dos alimentos

Fonte: Adaptado de Nações Unidas (2018).

Tanto em grandes como em pequenas unidades de produção, de caráter familiar, são utilizadas técnicas de produção, práticas e manejos produtivos altamente insustentáveis, tanto no viés econômico como social e ambiental. De 2005 a 2015, o mercado de agrotóxicos cresceu aproximadamente 190\% no Brasil. Desde 2008, o país lidera o ranking mundial de consumo de agrotóxicos. Dados da Anvisa apontam que muitos dos alimentos que chegam à mesa dos brasileiros tem resíduos de agrotóxicos acima dos limites tolerados.

Essas informações fazem emergir por parte da sociedade, de produtores à consumidores, resistências em torno da qualidade dos alimentos que chegam à mesa 
produzidos por esses meios de produção, o que podemos entender enquanto autoconfrontações como afirma Beck (2009). A agroecologia é uma das formas de produzir alimentos com sustentabilidade, com respeito as especificidades locais, tanto ambientais como humanas. Ademais, alimentos saudáveis, diversificados e frescos, que respeitem os hábitos alimentares das diversas populações requer também, estratégias para o fortalecimento da produção familiar e dos circuitos curtos de comercialização.

Com relação aos hábitos alimentares da população brasileira, vem se identificando uma constante modificação, com uma busca maior por alimentos frescos, com origem e processos de produção transparentes. Neste sentido, os circuitos curtos de comercialização, com destaque as feiras livres, têm se mostrado estrategicamente promissores no propósito de efetivar o escoamento da produção de muitos agricultores familiares. As feiras livres caracterizam-se por ocorrerem em espaços públicos e com periodicidade, são locais onde ocorrem trocas de mercadorias entre produtores, contato direto entre produtores e consumidores, além de propiciar o escoamento da produção agrícola local (Pierri e Valente, 2015).

Guzzatti, Sampaio e Turnes (2014), definem o circuito curto como sendo a comercialização de produtos agrícolas, que visam o estabelecimento de relações mais diretas entre agricultores e consumidores. E ainda, segundo Pierri e Valente (2015), os circuitos curtos são significativos para a economia local, pois propiciam geração de trabalho e renda, além de oferta de alimentos saudáveis.

Conforme Scarabelot e Schneider (2012), o estudo das cadeias agroalimentares curtas sugere formas de comercialização da produção agrícola com maior proximidade entre produtores e consumidores, permitindo uma vinculação com maior interatividade na construção mútua de relações de confiança. Mercados emergentes formam-se a partir do âmbito local e do relacionamento direto entre compradores e vendedores na lógica do estabelecimento de cadeias curtas de mercantilização.

François (2000, p.13) contribui para a definição de circuitos curtos ao afirmar que estes são uma forma de comercializar os produtos permitindo "diminuir o número de intermediários entre o produtor e o consumidor". O circuito mais curto é aquele em que o produtor entrega diretamente o seu produto ao consumidor, a chamada 'venda direta'. Estes circuitos tem a capacidade de caracterizar o território e reforçar a especificidade dos 
produtos. Estas formas de venda, através da ligação mais estreita entre o território, o cliente e o produto, reforçam o caráter de proximidade da produção local, bem como a constituição de novos usos do território (Santos; Silveira, 2004).

A agricultura familiar, neste sentido, é protagonista na constituição dos circuitos curtos de comercialização e, consequentemente, da efetivação dos usos do território, uma vez que tem sido responsável por boa parte da produção de alimentos. Na medida em que muitos agricultores familiares que não se enquadravam nas exigências tecnológicas que as agroindústrias impunham, viram-se forçados a buscar estratégias e alternativas, a fim de sobreviver e manter-se na agricultura. Para isso, adotaram dinâmicas diferenciadas, que se caracterizam através de um processo de diversificação de cultivos e atividades na propriedade e fora dela. Os circuitos curtos estão diretamente relacionados a este cenário. François (2000) infere que as novas tendências do consumo, que levam cada vez mais à procura de produtos saudáveis, naturais, com uma identidade ligada a um território, oferecem novas oportunidades de mercado para os produtos das zonas rurais.

Os circuitos curtos se configuraram em oportunidades para aumentar o valor agregado (François, 2000) e, ao mesmo tempo, permitem diminuir o número de intermediários entre o produtor e o consumidor. Segundo François (2000),

\footnotetext{
Estes circuitos constituem oportunidades para criar valor acrescentado no território e reforçar a especificidade dos produtos. Estas formas de venda, através da ligação estreita que estabelecem entre o território, o cliente e o produto, reforçam o caráter não deslocalizável da produção local. No entanto, para colocar os produtos no mercado através dos circuitos curtos só uma ação rigorosa permite minimizar os riscos de se aventurar em iniciativas sem saída e onerosas em termos de investimentos (François, 2000, p. 13).
}

Ademais, a venda através dos circuitos curtos permite melhorar os preços dos produtos. Em geral, o consumidor final paga menos e o produtor recebe mais. Também permite realizar localmente o trabalho de venda, colaborando assim para a manutenção dos empregos no território.

Os circuitos curtos de comercialização tendem a contribuir para a promoção do desenvolvimento regional em suas diferentes dimensões. Economicamente representam uma alternativa de renda para os agricultores familiares, apresentando enquanto aspecto positivo uma melhor remuneração do agricultor, uma vez que exclui o atravessador, pela venda direta. Socialmente, tendem a valorizar a cultura alimentar local/regional, por serem 
produzidos para o mercado, produtos típicos do consumo das famílias, contribuindo também para a SAN. Ambientalmente, contribuem com a manutenção da biodiversidade, uma vez que os circuitos curtos despendem menos energia para o transporte dos produtos, além de fomentarem uma produção diversificada nas propriedades, incentivada pelos diferentes canais curtos. Desse modo, contribuem para o desenvolvimento na escala humana, pois se concentram e se sustentam na satisfação das necessidades humanas fundamentais, na geração de níveis crescentes de autoconfiança, na articulação orgânica dos seres humanos com a natureza e a tecnologia. O desenvolvimento se fortalece na interação do pessoal com o social, do planejamento com a autonomia e da sociedade civil com o Estado (Boisier, 2001).

\section{Considerações sobre os Núcleos de Estudo em Agroecologia e Produção Orgânica (NEAs) no Brasil}

Nos últimos 15 anos, uma mudança significativa iniciou nos espaços das IES brasileiras. Segundo Sousa (2011), foram criadas, a partir de 2001, dezenas de cursos de ensino médio profissionalizante em Agroecologia, além de cursos de graduação e pósgraduação reconhecidos pela Coordenação de Aperfeiçoamento de Pessoal de Nível Superior (Capes).

Adjunto a essa inserção dos referidos cursos, a agroecologia passa a ser abordada nas mais diversas instancias dentro das Instituições de Ensino do país. E um exemplo é a criação dos Núcleos de Estudo em Agroecologia e Produção Orgânica (NEAs). Um NEA constitui um centro de referência para o desenvolvimento rural sustentável fundamentado nos princípios, conhecimentos e práticas da agroecologia, da produção orgânica e de base agroecológica, por meio de ações que integrem atividades de ensino, pesquisa e extensão em sua área de influência, tal como indicam documentos do CNPq.

Ao longo do tempo, os NEAs têm se constituído em espaços de diálogo e de exercício da indissociabilidade entre pesquisa-ensino-extensão, estando em constante e permanente interação com a sociedade, pois os Núcleos tem procurado estabelecer parcerias com organizações sociais, instituições públicas e privadas e comunidades, possibilitando assim levar a cabo processos científicos-acadêmicos e tecnológicos com profundos lastros sociais. 
Destaca-se que a constituição dos primeiros NEAs foi fomentada por meio de chamadas públicas lançadas pelo Conselho Nacional de Desenvolvimento Científico e Tecnológico (CNPq), com aporte financeiro dos ministérios envolvidos com o tema. As primeiras chamadas específicas para a agroecologia ocorreram com o lançamento da Carta Convite no 73/2010 (Mapa/MCTI ${ }^{4} / \mathrm{MEC}^{5}$ ), para o fomento de 27 NEAs na Rede Federal de Educação Profissional, Científica e Tecnológica e da Chamada no 58/2010 (MDA ${ }^{6} / \mathrm{SAF}^{7} / \mathrm{CNPq}$ ) que apoiou a criação de 52 NEAs nas Universidades brasileiras. Em 2012, a Chamada no 46/2012 (MCTI/MEC/Mapa/CNPq) foi lançada em um esforço de continuação do apoio à implantação e/ou manutenção de NEAs nas instituições da Rede Federal de Educação Profissional, Científica e Tecnológica. Em 2013, a partir de um esforço conjunto de vários ministérios visando apoiar atividades de pesquisa, educação e extensão voltadas para a construção e socialização de conhecimentos e práticas relacionados à agroecologia e aos sistemas orgânicos de produção, foi lançada a Chamada no 81/2013 (MCTI/Mapa/MDA/MEC/MPA ${ }^{8} / \mathrm{CNPq}$ ) (Souza, 2017).

Em 2014, com a participação da Comissão Nacional de Agroecologia e Produção Orgânica (Cnapo) e o apoio da Associação Brasileira de Agroecologia (ABA) e da Articulação Nacional de Agroecologia (ANA), duas novas chamadas são lançadas MDA/CNPQ no 38/2014 e MDA/CNPq no 39/2014. A primeira para fomento de NEAs na Empresa Brasileira de Pesquisa Agropecuária (Embrapa) e nas Organizações Estaduais de Pesquisa (Oepas) e a segunda para o fomento de Redes de Núcleos de Estudo em Agroecologia e Sistemas Orgânicos de Produção (R-NEAs) nas regiões Norte, Nordeste e Centro-Oeste e de novos NEAs em universidades públicas e privadas sem fins lucrativos que não tiveram apoio na Chamada no 81/2013 (Silva, 2017).

No início de 2016, foi lançada a Chamada Pública no 02/2016 (MCTI/Mapa/CNPq) de apoio à implementação e/ou manutenção de NEAs em instituições da Rede Federal de Educação Profissional, Científica e Tecnológica, como continuidade às chamadas de NEAs específicas para os institutos federais. Já no final de 2016, foi lançada a Chamada no 21/2016 (MCTIC/Mapa/MEC/SAF-Casa Civil/CNPq), com a finalidade de apoiar a implantação e

\footnotetext{
${ }_{5}^{4}$ Ministério da Ciência, Tecnologia e Informação.

${ }^{5}$ Ministério da Educação.

${ }_{7}^{6}$ Ministério do Desenvolvimento Agrário.

${ }^{7}$ Secretaria de Agricultura Familiar (SAF).

${ }^{8}$ Ministério da Pesca e Aquicultura.
} 
manutenção de NEAs e Centros Vocacionais Tecnológicos de Agroecologia e Produção Orgânica CVTs (CVTs) em universidades públicas, privadas sem fins lucrativos e para instituições da Rede Federal de Educação Profissional, Científica e Tecnológica (Souza, 2017).

Ao total, entre 2010 e 2016 foram apoiados 373 projetos envolvendo os NEAs com aporte de recursos de aproximadamente R\$ 62 milhões investidos. Ver a tabela 1.

Tabela 1 - Projetos e recursos aportados aos NEAs

\begin{tabular}{c|c|c|c|c}
\hline Ano & Chamada/ação & Ministério & $\begin{array}{c}\text { Projetos } \\
\text { apoiados }\end{array}$ & $\begin{array}{c}\text { Recursos } \\
\text { aportados (R\$) }\end{array}$ \\
\hline 2010 & Carta Convite n.73/2010 & Mapa/MCTI/MEC & 27 & $1.012 .000,00$ \\
\hline 2010 & Chamada n.58/2010 & MDA & 52 & $5.400 .000,00$ \\
\hline 2012 & Chamada n. 46/2012 & Mapa/MCTL/MEC & 22 & $8.900 .000,00$ \\
\hline 2013 & Chamada n.81/2013 & Mapa/MCTI/MEC/MDA/MPA & 93 & $30.000 .000,00$ \\
\hline 2014 & Chamada n.38/2014 & MDA & 25 & $2.000 .000,00$ \\
\hline 2014 & Chamada n.39/2014 & MDA & 19 & $4.600 .000,00$ \\
\hline 2016 & Chamada n.02/2016 & MCTIC/Mapa & 44 & $4.074 .956,00$ \\
\hline 2016 & Chamada n.21/2016 & MCTIC/Mapa/MEC/SAF & 91 & $10.700 .000,00$ \\
\hline Total & - & - & $\mathbf{3 7 3}$ & $\mathbf{6 2 . 6 1 2 . 0 0 0 , 0 0}$ \\
\hline
\end{tabular}

Fonte: Adaptado de Souza et al. (2017).

Segundo Silva et al (2017), a maioria dos projetos de Núcleos estão nas universidades (56\%), seguidos pelos Institutos Federais (26\%) e centros de pesquisa (15\%), sendo 39 Institutos Federais; 49 Universidades Federais; 21 Universidades Estaduais; e 5 Universidades sem fins lucrativos. Quanto à distribuição geográfica, estão presentes nos 27 estados da Federação: 12 NEAs se localizam-se na região Centro Oeste, 21 na região Norte, 39 na região Sul, 41 na região Nordeste e 42 na Sudeste, atendendo em torno de 60 mil beneficiários diretos entre estudantes, professores, agricultores e agricultoras familiares, técnicos da extensão rural, entre outras.

Os Núcleos vêm realizando diferentes ações e avaliações acerca de sua atuação. Por exemplo, o NEA Ajuri tem atuado em cursos de capacitação ofertados para agentes de extensão rural, sujeitos ligados aos movimentos sociais do campo, estudantes, agricultores e membros de diversos Núcleos de agroecologia do Pará e da Rede de Núcleos de Experiências Agroecológicas da região Norte (Silva et al, 2016). Já Prezatti et al (2001) descrevem que no Instituto Federal de Educação, Ciência e Tecnologia do Espírito Santo - Campus Santa Teresa (Ifes-ST), o NEA tem tido importância significativa no processo de "desconstrução" do saber formatado, baseado no modelo exclusivamente convencional. Por meio de debates, estudos 
de caso, excursões técnicas e oficinas, vem fomentando na instituição a construção do conhecimento na perspectiva da sustentabilidade, em todas as suas dimensões.

De acordo com Buquera et al (2018), o Núcleo de Agroecologia Apetê-Caapuã (NAAC) da Universidade Federal de São Carlos (UFSCar), atua junto a agricultores, instituições públicas, privadas e movimentos sociais na região Sorocabana, com o objetivo de promover uma agricultura de base ecológica e contribuir para que agricultores familiares tenham vida digna, saudável, com bem-estar e renda, a partir dos princípios da Agroecologia. Ações têm sido realizadas, como eventos regionais, campanhas, cursos, feiras, pesquisas científicas e atividades de extensão, valorizando aspirações da população local. Enquanto resultados os autores destacam a aproximação da universidade com a realidade da agricultura familiar, além da formação técnica e política de membros do NAAC e o fortalecimento da Articulação Paulista de Agroecologia. Percebem cada vez mais o engajamento político e social diante dos assuntos atuais diretamente relacionados com a temática abordada (transgênicos, código florestal, reforma agrária, políticas públicas e situação política do país) possibilitando correlacionar o conhecimento acadêmico com a realidade e as necessidades da região de Sorocaba.

Pasqualotto et al (2018) analisam a atuação do Núcleo de Estudos em Agroecologia, Agrobiodiversidade e Sustentabilidade Prof. José Antônio Costabeber, da Universidade Federal de Santa Maria (NEA-UFSM). Com ações desde 2012 no território Central do Rio Grande do Sul, trabalhou no monitoramento da sustentabilidade de oito agroecossistemas em transição agroecológica, sistematizando as experiências dessas famílias, o que possibilitou a compreensão das dinâmicas sociais, ambientais e econômicas presentes em cada agroecossistema.

Apesar das repercussões territoriais apontadas, as quais refletem avanços nas experiências agroecológicas e nos processos de desenvolvimento regional, apenas Petry et al (2018) e Paiva et al (2018) tratam objetivamente do NEA enquanto mecanismo capaz de fortalecer a relação produtor-consumidor e os circuitos curtos de comercialização.

Petry et al (2018) fazem uma análise da relação entre consumidor consciente e agricultor agroecológico no âmbito do NEA-UPF, na região do planalto médio do Rio Grande do Sul. Numa articulação da Universidade de Passo Fundo (UPF), envolvendo cursos de Agronomia, Farmácia, Biologia, Nutrição, Saúde Coletiva em parceria com o Centro de 
Tecnologias Alternativas Populares (Cetap), a Cooperativa Mista e de Trabalho Alternativa (Coonalter), a Feira Ecológica de Passo Fundo e o Núcleo Planalto da Rede Ecovida, o NEA avalia que obteve resultados regionais, com representação no território. Houve aumento crescente de demanda dos produtos da feira ecológica, estabelecimento de diálogo de profissionais da agronomia com profissionais da saúde. A partir deste diálogo, constata-se a existência de um forte vínculo entre agroecologia e a saúde. Petry et al (2018) enfatizam que a saúde é um direito do povo, que tem no NEA-UPF um aliado coletivo. A agroecologia sensibiliza e se mostra possível economicamente dentro de regiões o planalto médio onde o agronegócio impera. Salientam que, no entanto, será o consumidor quem vai mudar a relação de poder ao escolher saúde através do consumo de alimentos orgânicos.

Paiva et al (2018) ao sistematizar as ações do NEA-UFRGS, buscaram identificar as restrições de natureza tecnológica e gerencial das agroindústrias familiares processadoras de alimentos orgânicos no Rio Grande do Sul e propor ações mitigatórias. Assim, para instrumentar essa transição dos sistemas produtivos agrícolas e agroindustriais os autores explicitam ações denominadas pontuais e concretas, das quais destacamos o apoio a construção de cadeias curtas agroalimentares ecológicas.

\begin{abstract}
As relações de proximidade sócio espaciais entre agricultores e consumidores na comercialização dos alimentos de base ecológica são fundamentais. Isso já ocorre na maioria das experiências. Para os agricultores as chamadas cadeias curtas de comercialização, reduzem custos de produção, transação, eliminam os intermediários e aumentam o valor agregado e a renda gerada com as vendas dos alimentos. Do lado dos consumidores, há a possibilidade de comprar produtos mais saudáveis, preservando a saúde e o meio ambiente e reduzindo seus desembolsos econômicos, se comparados aos comprados no varejo alimentar. Os agentes de desenvolvimento e o Estado poderiam pensar mecanismos de aproximação entre produção e consumo, por exemplo, fomentando a criação de redes agroalimentares locais como grupos de consumo organizados, feiras de alimentos orgânicos, financiando a construção de pontos de venda a beira das estradas e em locais com maior movimentação de pessoas, estruturando centrais de distribuição dos produtos, entre outras iniciativas que fortaleceriam estas vendas locais e regionais dos alimentos. Neste sentido, outras duas ações que beneficiariam as iniciativas são a ampliação dos valores em compras institucionais pelos programas governamentais (PAA e PNAE) dos alimentos de base ecológica, bem como dar prioridade a este frente os demais produzidos pela agricultura familiar. Estas ações fortaleceriam os circuitos locais de produção-consumo, bem como as cadeias curtas de comercialização (Paiva et al, 2018, p.113).
\end{abstract}

Nesse sentindo, e dadas as discussões anteriores sobre o aumento da fome e o constante crescimento da obesidade nas escalas nacional e global, além dos impactos 
ambientais decorrentes da modernidade, defende-se que estratégias como os NEAs, que resultam em uma articulação entre Estado, Universidades e sociedade civil, incluindo produtores e consumidores, merece ser pensada enquanto um mecanismo de fortalecimento de circuitos curtos de comercialização, de modo a constituir dinâmicas territoriais de desenvolvimento regional capazes de promover (a) o aperfeiçoamento do território, entendido não como um container e suporte físico de elementos naturais, mas como um sistema físico e social estruturalmente complexo, dinâmico e articulado; (b) o aperfeiçoamento da sociedade ou comunidade que habita esse território; (c) o aperfeiçoamento de cada pessoa que pertence a essa comunidade e que habita esse território (Boisier et al, 1995).

Embora Silva et al (2017) enfatizem que a política de criação de NEAs nas IES pode ser considerada uma importante catalisadora e promotora do estreitamento entre estas instituiç̧̃̃es e o espaço rural, permitindo ao Estado cumprir seu papel no tocante à geração e disseminação de conhecimentos científicos e tecnológicos que possam gerar qualidade de vida e promover um desenvolvimento mais justo e com sustentabilidade, destaca-se aqui que esta iniciativa pode abarcar uma dimensão para além do espaço rural, abarcando a escala regional.

\subsection{Considerações sobre o processo de criação do NEA Litoral Norte}

O Litoral Norte possui uma importante trajetória de implementação de iniciativas agroecológicas. As primeiras ações nesta região, datam no início dos anos 1990, quando foi criada a Associação dos Colonos Ecologistas da Região de Torres (Acert).

A Acert é constituída a partir de um movimento que inicia na Serra Gaúcha e que dá origem ao Centro Ecológico. O Centro é uma ONG, criada em 1985, que trabalha para viabilizar avanços sustentáveis na produção agrícola, mediante a adoção de tecnologias alternativas orientadas pela filosofia da preservação ambiental e da justiça social, por meio de visitas, reuniões, cursos e oficinas de capacitação e planejamento (Centro Ecológico, 2018). O Centro Ecológico está estruturado nos núcleos Ipê-Serra e Litoral Norte.

A partir da Acert outras famílias se engajaram em práticas de produção agroecológica e fundam novos grupos, associações e cooperativas. Destaca-se a Associação dos Produtores 
Ecologistas da Luz do Canto dos Magnus (Apelcam), a Associação dos Produtores Ecologistas de Morrinhos do Sul (Apemsul), Cooperativa de Consumidores de Produtos Ecológicos de Três Cachoeiras (Coopet), Consumidores de Produtos Ecológicos de Torres (Ecotorres), Produtores Ecologistas do Litoral Norte do RS e Sul de SC (Econativa); Agricultores Familiares de Itati, Terra de Areia e Três Forquilhas (COOMAFITT, 2018).

A trajetória de atuação do Centro Ecológico e da Acert impulsionam a criação do Núcleo Litoral Solidário da Rede Ecovida de Agroecologia. Esta é uma articulação existente na região Sul do Brasil entre organizações sociais de agricultores, técnicos e consumidores. Visa fortalecer a agroecologia, a organização e a reprodução social da agricultura familiar agroecológica (Souza, 2008). Conta atualmente com 27 núcleos regionais, abrangendo cerca de 352 municípios. Seu trabalho congrega, aproximadamente, 340 grupos de agricultores, abrangendo cerca de 4.500 famílias envolvidas e 20 ONGs. Em toda a área de atuação da Ecovida acontecem mais de 120 feiras livres ecológicas além de outras formas de comercialização (Ecovida, 2018).

No Núcleo Litoral Solidário há cerca de 250 famílias organizadas em 27 grupos e associações agroecológicas, localizadas nos municípios de Torres, Dom Pedro de Alcântara, Morrinhos do Sul, Mampituba, Três Cachoeiras e Osório (Souza, 2008). Também fazem parte desse núcleo regional as cooperativas de consumidores dos municípios de Três Cachoeiras (Coopet), de Torres (Ecotorres), o Centro Ecológico, a ONG Ação Nascente Maquiné (Anama), a Teia de Educação Ambiental Mata Atlântica, a Agroindústria Morro Azul e a cooperativa de produtores Econativa (Mapa da Agroecologia, 2018).

Outra iniciativa importante desenvolvida na região é a criação do Organismo Participativo de Avaliação da Conformidade (OPAC), Litoral Norte. Este é formado por agricultores e consumidores de produtos orgânicos, atualmente em um total de 24 sócios, com parceria da Empresa de Assistência Técnica e Extensão Rural (Emater/RS-Ascar). Os membros da entidade são de diferentes municípios do Litoral Norte sendo criado em 2012. Possui atualmente sede administrativa no município de Itati, junto à Cooperativa Mista de Agricultura Familiar de Itati, Terra de Areia e Três Forquilhas (COOMAFITT).

O breve relato sobre as diversas iniciativas implementadas em torno da agroecologia no Litoral Norte caracteriza um mosaico de experiências que constituem um potencial a ser 
fomentado, na medida em que se compreende a agroecologia enquanto uma importante estratégia de desenvolvimento regional, uma vez que, como aponta Guzmán (2007),

La globalización agroalimentaria amenaza el patrimonio cultural y material
agroganadero, rural y alimentario a la vez que contribuye a profundizar la crisis
ecológica en la que vivimos. La alteración del equilibrio de los agroecosistemas se
entrelaza con los mecanismos de exclusión social que acompañan a la creciente
dependencia del mercado. La Agroecología propone un enfoque de análisis
alternativo para la comprensión del manejo y diseño de los agroecosistemas así
como propuestas para el desarrollo rural y alimentario basado en la recuperación
de los conocimientos y formas de organización sociocultural campesinas (GUZMÁn,
2007, p.191).

Assim, em uma região que, para além de seu reconhecido potencial turístico em torno das praias, apresenta uma agricultura familiar significativa, com diversas iniciativas agroecológicas, uma população culturalmente diversa, além de ecossistemas frágeis a agroecologia desponta como uma possibilidade real de promoção do desenvolvimento regional.

Contudo, a emergência dessas entidades não abriu caminho para a comercialização de produtos agroecológicos na região como um todo. Municípios de expressão significativa em termos populacionais como Osório, Tramandaí e Capão da Canoa não dispõe de locais e centros de comercialização específicos de produtos agroecológicos, ou seja, a produção agroecológica do Litoral Norte acaba contemplando o mercado agroecológico de grandes cidades como Caxias do Sul, Porto Alegre e Canoas.

O que desponta como um aspecto limitante na construção social de mercados da agroecologia na região são as ainda frágeis relações entre as diferentes organizações, bem como a desmobilização, desconhecimento ou desinteresse dos consumidores. A existência de uma Rede das Entidades poderia, por exemplo, estimular a produção e consumo, este último, podendo ser fomentado por grupos de consumidores na região.

Atentando a essa questão, o campus Litoral da Universidade Federal do Rio Grande do Sul (UFRGS), criado em 2014, vem trabalhando no sentido de implementar o Núcleo de Estudos em Agroecologia e Produção Orgânica - NEA Litoral Norte.

Após diversos debates junto ao NEA Litoral Norte, em torno das problemáticas citadas, uma das ações realizadas, foi a organização de um grupo de consumidores (inicialmente composto somente por docentes e técnicos), para a estruturação de compra direta dos produtores dos agricultores agroecologistas. Uma consulta inicial, apontou 37 
pessoas (dentre um grupo de aproximadamente 70 ) interessadas na ação. Envolvendo atividades de ensino, pesquisa e extensão, passou-se a organizar produtores e consumidores em uma relação mais direta, sendo que em 11 de maio de 2017, ocorreu a primeira entrega de produtos orgânicos e/ou agroecológicos, no Campus Litoral, com uma oferta de 69 produtos, dentre frutas, legumes, verduras, chás, etc (figura 1). Estão envolvidos com o grupo de consumidores, cinco famílias de produtores e uma média de 30 famílias consumidoras, dos municípios de Osório, Tramandaí, Imbé, Cachoerinha e Porto Alegre.

Figura 1 - Primeira entrega de produtos orgânicos/agroecológicos no Campus Litoral da UFRGS
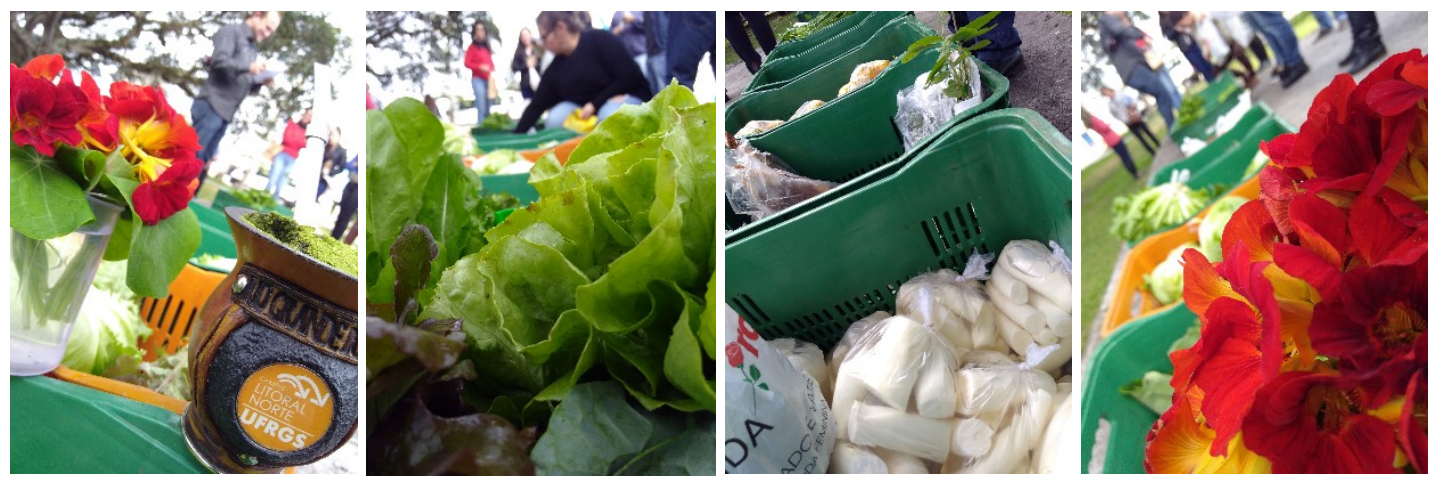

Fonte: Felipe Marcarenhas.

A dinâmica de funcionamento é a seguinte: a) os produtores (através de um mediador) enviam ao grupo de consumidores (através de um mediador), nas terças-feiras um e-mail contendo os produtos disponíveis para serem entregues às quintas-feiras; b) os consumidores de posse da lista preenchem uma planilha no google docs com seu pedido até as $12 \mathrm{~h}$ das quartas-feiras; c) a planilha com a quantidade de produtos solicitados é imediatamente repassada aos produtores; d) nas quintas-feiras, das $15 \mathrm{~h}$ às $16 \mathrm{~h}$ ocorre a entrega, momento em que os consumidores retiram os produtos e fazem o pagamento diretamente ao produtor (responsável pela entrega). A entrega ocorre com observação e apoio da comunidade acadêmica, a qual dialoga com os produtores e consumidores sobre o tema, despertando interesse dos alunos e funcionários terceirizados da Universidade, que a cada entrega reiteram o interesse em adquirir os produtos. No entanto, momentaneamente as ações estão vinculadas ao grupo que tem participado dos debates e projetos, em prol de estudar as ações agroecológicas que estão sendo desenvolvidas na região, em seus múltiplos aspectos. 
Os projetos atualmente em curso via o NEA Litoral Norte, têm previsão de se estender até o final do segundo semestre de 2018, abrangendo reuniões e diálogos com diferentes atores sociais e políticos que atuam nos temas das políticas públicas, agricultura familiar e agroecologia. E especificamente a consolidação do NEA Litoral Norte tem como intensão atuar no fortalecimento da integração de ações da Universidade com ações da sociedade civil via atividades de ensino, pesquisa e extensão em torno da sustentabilidade ambiental local e regional. Contudo, ações mais efetivas e à médio e longo prazos demandam fontes de financiamento, como os editais do CNPq.

\section{Considerações finais}

Considerando que o mercado mundial de alimentos é marcado por um processo de oligopolização, no qual grandes corporações transnacionais produzem e ofertam alimentos padronizados, buscou-se evidenciar que, cada vez mais, sistemas alternativos vem sendo construídos, tais como os circuitos curtos de comercialização, pelos quais é possível uma (re) aproximação entre produtores e consumidores, e uma redefinição das relações com o mercado, contribuindo assim na promoção do desenvolvimento regional.

Defende-se que a criação de Núcleos de Agroecologia e Produção Orgânica (NEAs) é uma importante iniciativa que habilita a construção de sistemas agroalimentares alternativos, que reconhecem saberes dos agricultores familiares, fortalecem relações mais sustentáveis com o ambiente e contribuem com a soberania e segurança alimentar das regiões.

Mediante o crescimento da população mundial, que deva alcançar 10 bilhões até 2050, e junto a isso, o recente aumento da fome no mundo que corre paralelamente ao crescimento da obesidade, ressalta-se que tais problemas dificilmente serão resolvidos pelo simples incremento da produção e exportação de commodities. Muito embora essa estratégia possa diminuir a fome, o mesmo pode não ocorrer em relação à obesidade, uma vez que os impérios agroalimentares (Ploeg, 2008) baseiam-se em alimentos padronizados, processados e pouco variados.

Frente a isso, entende-se que o fomento aos mais diversos circuitos curtos de comercialização deve perpassar os objetivos e as estratégias governamentais, seja para 
promover soberania e segurança alimentar e nutricional, seja para fomentar economias locais/regionais, ou ainda, para promover ações mais adequadas à manutenção dos agroecossistemas.

Por outro lado, o consumidor não pode ser desconsiderado nessa dinâmica, pois parte considerável dos circuitos curtos já existentes decorrem da demanda dos próprios consumidores por alimentos mais saudáveis - frescos, variados, orgânicos ou agroecológicos. Portanto, este é um ator chave no fortalecimento dos circuitos curtos de comercialização, no estabelecimentos de novas e mais próximas relações entre produtor e consumidor. Entende-se que estas relações podem construir alternativas ao poder hegemônico das grandes corporações transnacionais que produzem e ofertam alimentos padronizados.

Frente a isso, o NEA Litoral Norte, que é uma iniciativa incipiente, representa uma estratégia, dentre muitas outras possíveis, de fortalecimento dos circuitos curtos de comercialização no Litoral Norte gaúcho, considerando principalmente a existência de produção orgânica/agroecológica por um lado, e por outro, a inexistência de mercados para estes produtos na própria região. É fundamental, portanto, o fortalecimento do NEA e a realização de diferentes ações que mobilizem produtores e consumidores.

\section{Referências}

BECK, U. World at Risk. Cambridge: Polity Press, 2009.

BOISIER, S. Desarrollo (Local): ¿'De que estamos hablando? In: MADOERY, Oscar; VÁZQUEZ BARQUERO, Antonio (Orgs.) Transformaciones Globales, Instituciones y Políticas de Desarrollo Local. Rosario: Homo Sapiens, 2001.

BOISIER, Sergio et al. Sociedad civil, actores socielies y desarrollo regional. Santiago do Chile: Ilpes/Cepal, 1995.

CENTRO ECOLÓGICO. Assessoria e Formação em Agricultura Ecológica. Disponível em: $<$ http://www.centroecologico.org.br/>. Acesso em ago/2018.

COMAFITT. Cooperativa Mista de Agricultores Familiares de Itati, Terra de Areia e Três Forquilhas. Disponível em: < www.coomafitt.com.br>. Acesso em: ago/2018. 
FAO. Food and Agriculture Organization of the United Nations. Representante da FAO Brasil apresenta cenário da demanda por alimentos. Disponível

em:<http://www.fao.org/brasil/noticias/detail-events/en/c/901168/>. Acesso em ago/2018.

FRANÇOIS, Martine. Comercializar os produtos locais: circuitos curtos e circuitos longos. Inovação no meio rural. Caderno no 7. Observatório Europeu LEADER. Julho de 2000.

GUZMAN, Eduardo Sevilla; Agroecología y soberanía alimentaria: alternativas a la globalización agroalimentaria. Patrimonio cultural en la nueva ruralidade, Ph Cuadernos, 2007, 191. Disponível em:

<http://www.iaph.es/export/sites/default/galerias/documentacion_migracion/Cuaderno/12 79619840882_agroecologia_y_soberania_alimentaria.pdf > Acesso em: mar/2018.

GUZZATTI, T. C.; SAMPAIO, C. A. C. \& TURNES, V. A. Novas relações entre agricultores familiares e consumidores: perspectivas recentes no Brasil e na França. Organizações Rurais \& Agroindustriais, 2014, v. 16 (3). 2014. pp. 363-375

MAPA DA AGROECOLOGIA. Disponível em: <https://mapadaagroecologia.org/locais/nucleolitoral-solidario-da-rede-ecovida-de-agroecologia?locale=pt-BR>. Acesso em: ago/2018.

MARSDEN, T.; BANKS, J.; BRISTOW, G. Food suply chain approaches: exploring their role in rural development, Sociologia Ruralis, 2000, vol. 40, n. 4, pp. 424-438.

NAÇÕES UNIDAS. 17 Objetivos do Desenvolvimento Sustentável. Disponível em:<https://nacoesunidas.org/pos2015/ods2/>. Acesso em: ago/2018.

PASQUALOTTO, Nayara et al. Conectando experiências agroecológicas no território central do Rio Grande do Sul. Revista Brasileira de Agroecologia, v. 13, n. 1, jan. 2018. Disponível em: <http://revistas.aba-agroecologia.org.br/index.php/rbagroecologia/article/view/ 22457>. Acesso em: ago/2018.

PETRY, Claudia et al. NEA-UPF consolidando a rede agroecológica de cidadãos saudáveis no planalto médio gaúcho: do consumidor consciente ao agricultor agroecológico. Revista Brasileira de Agroecologia, v.13, n. Esp.,2018.

PIERRI, M. C. Q. M. \& VALENTE, A. L. E. F. (2015) A feira livre como canal de comercialização de produtos da agricultura. Anais. In: 53ํㅡㄹ Congresso de Economia e Sociologia Rural. Alagoas.

PLOEG, J. D. V. D. Camponeses e impérios alimentares. Porto Alegre, editora da UFRGS, 2008.

PREZOTTI, Lusinério et al. Núcleo de Desenvolvimento Agroecológico - NDA: experiência de construção do conhecimento agroecológico no ensino médio integrado em agropecuária do Ifes campus Santa Teresa - ES. Cadernos de Agroecologia, v. 6, n. 2, Dez 2011. Disponível em:< http://revistas.aba-agroecologia.org.br/index.php/cad/article/view/12652/7109>. Acesso em ago/2018. 
REDE ECOVIDA. Rede de Agroecologia. Disponível em: <http://ecovida.org.br/>. Acesso em: ago/2018.

RENTING, Henk; MARSDEN, Terry; BANKS, Jo. Understanding Alternative Food Networks: Exploring the Role of Short Food Supply Chains in Rural Development. Environment and Planning, n.35, p.393-411, 2003.

SANTOS, Milton; SILVEIRA, Maria Laura. O Brasil: território e sociedade no início do século XXI. 6.ed., Rio de Janeiro: Record, 2004.

SCARABELOT, M. \& SCHNEIDER, S. As cadeias agroalimentares curtas e desenvolvimento local: Um estudo de caso do município de Nova Veneza, SC. Revista Faz Ciência. 2012. V.15 (20). 101-130.

SILVA, Josefa E. M. et al. O mutirão de relações agrooecológicas do Núcleo Apête-Caapuã: tecendo redes na região Sorocabana. Revista Brasileira de Agroecologia, [S.I.], v. 13, n. 1, jan. 2018. Disponível em: <http://revistas.aba-

agroecologia.org.br/index.php/rbagroecologia/article/view/22441>. Acesso em: ago/2018.

SILVA, L. M S.; SOUSA, R. da P.; ASSIS, W. S. de. A educação superior e a perspectiva agroecológica: avanços e limites dos Núcleos de Agroecologia das IES no Brasil. Redes - Santa Cruz do Sul: Universidade de Santa Cruz do Sul, v. 22, n. 2, maio-agosto, 2017.

SILVA, Luis, M. S. et al. O papel dos NEAs em processos continuados de formação: a experiência do NEA AJURI, no estado do Pará. Cadernos de Agroecologia. v. 12, n. 1, Jul. 2017a. Disponível em:< http://revistas.abaagroecologia.org.br/index.php/cad/article/view/22320/12779>. Acesso em: ago/2018.

SOUSA, Romier et al. Núcleo de Estudos em Agroecologia: a construção de uma (re)ação na Amazônia paraense. Cadernos de Agroecologia. v. 11, n. 1, jun/2016.

SOUSA, R. da P. Rompiendo las cercas: formación profesional y Agroecología: uma mirada crítica de una experiencia en la Amazonia brasileña. Baeza: UNIA: UCO: UPO, 2011.

SOUZA, N. A. et all. Os Núcleos de Agroecologia: Caminhos e Desafios na Indissociabilidade entre Ensino, Pesquisa e Extensão. In: SAMBUICHI, Regina Helena Rosa, et al. (org.). A política nacional de agroecologia e produção orgânica no Brasil: uma trajetória de luta pelo desenvolvimento rural sustentável. Brasília: Ipea, 2017.

SOUZA, Julia Z. C. de. Comércio Solidário na Prática do Núcleo Litoral Solidário da Rede Ecovida de Agroecologia. Dissertação. (Mestrado em Desenvolvimento Rural). Universidade Federal do Rio Grande do Sul, Porto Alegre, 2008. 